University of Zurich

Department of Economics

Working Paper Series

ISSN 1664-7041 (print)

ISSN 1664-705X (online)

Working Paper No. 123

Non-homothetic preferences and industry directed technical change

Timo Boppart and Franziska J. Weiss

June 2013 


\title{
Non-homothetic preferences and industry directed technical change*
}

\author{
Timo Boppart ${ }^{\dagger}$ and Franziska J. Weiss ${ }^{\ddagger}$
}

June 6, 2013

\begin{abstract}
Sectoral data features (i) changing relative expenditures of different sectors, (ii) non-constancy in relative prices and (iii) long-run trends in relative TFP growth rates across sectors. We provide a tractable theory of industry directed technical change, which is able to reconcile these findings. In doing so, this paper emphasizes the importance of directed technical change, nonhomotheticity of preferences and structural change as a long-run phenomenon. Using the input-output tables of the U.S., our theory helps us to reconstruct how structural change in terms of final consumption affects the market size of industry value-added. Arguing that the structural change across broad categories of final consumption is exogenous from the perspective of an individual firm, this gives us an instrument for the industrial market size (at the valueadded level). We then empirically test for the market size effect of induced innovation. Our findings suggest that a 1 percent increase in an industry's market size (relative to GDP) leads to an increase in the TFP growth rate of about 0.3 percentage points over five years.
\end{abstract}

Keywords: Directed technical change, structural change, non-homothetic preferences, input-output tables, market size effect.

JEL classification: C67, O14, O31, O33, O41.

${ }^{*}$ We are grateful to Josef Falkinger and Fabrizio Zilibotti for fruitful discussions. Furthermore, we thank Berthold Herrendorf, Michelle Rendall, attendees at the DEGIT conference 2012 and the Spring Meeting of Young Economists 2013 and all seminar participants at the University of Leipzig and Zurich for their helpful comments. Franziska Weiss acknowledges financial support from the Swiss National Science Foundation. An earlier draft of this paper circulated under the title "Structural change, market size and sector specific endogenous growth".

${ }^{\dagger}$ IIES, Stockholm University and University of Zurich, Department of Economics. E-mail: timo.boppart@iies.su.se.

${ }^{\ddagger}$ University of Zurich, Department of Economics. E-mail: franziska.weiss@econ.uzh.ch. 


\section{Introduction}

Structural change - defined as changes in relative expenditures of different sectors - is according to Kuznets (1973) one of the six main features of modern economic growth and development. In addition, differences in productivity growth rates across sectors generate systematic relative price dynamics. The literature provides two theoretically robust mechanism which link the sector specific expenditure structure to relative prices: On the one hand, if sectors differ in their total factor productivity (TFP) growth rates, relative prices change over time and structural change can be the result. This mechanism was emphasized by Baumol (1967), who illustrates that the nominal expenditure structure is affected by relative price changes whenever the elasticity of substitution is unequal to unity. Ngai and Pissarides (2007) implement this channel in a neoclassical growth model with intertemporal optimization and balanced growth on the aggregate.

On the other hand, the literature on directed technical change emphasizes that changes in the relative market size of different sectors translate into changes in sector specific R\&D investments, which in turn determine the relative TFP growth rate and finally the dynamics of the relative price. This second mechanism goes back to Schmookler (1962) and Griliches and Schmookler (1963) and was first formalized in a dynamic general equilibrium setting in Acemoglu (1998), Acemoglu and Zilibotti (2001) and Acemoglu (2002). If expenditure shares change over time, a theory of induced innovation suggests that an increasing fraction of total R\&D activity concentrates on sectors with an increasing expenditure share. This intensified R\&D activity translates into an increase in the relative TFP growth rate and consequently into a decrease in the relative price growth of sectors with a rising output share. Interestingly, in these two theoretical approaches above, the causality of the link between expenditure shares and relative price dynamics runs in different directions. This makes empirical identification difficult and has contributed to the fact that em- 
pirical quantification of the two channels remains relatively rare. ${ }^{1}$ As an additional (theoretical) challenge, relative price changes are not the only driver of structural change. Whenever preferences are non-homothetic, income effects also determine the demand structure, along any growth path with increasing living standards. However, although there is ample evidence that this channel is quantitatively important, we are not aware of any theory of directed technical change which does allow for non-homothetic preferences.

The theoretical contribution of this paper is to provide a model of directed technical change in which structural change happens due to both relative price and income effects. In contrast to the standard theory of directed technical change, structural change will not only be a transitional dynamic but a long-run process, being present even asymptotically. Within the model, there are two final consumption goods which enter the instantaneous utility function of households. Both final goods are produced using an identical set of intermediate industries, varying only in the intensities with which these are used. Due to these intensity differences, structural change in terms of final output goods trickles down to a structural change in terms of industry value-added. Since the endogenous innovation process takes place at the industry level, changes in industrial market sizes induce a shift in industry specific R\&D investments, which finally determines the evolution of final output prices. Although the model replicates this rich, disaggregate production structure, it still features balanced growth on the aggregate in line with Kaldor's (1961) stylized facts and can be solved by paper and pencil.

In the empirical section, we use U.S. industry level data to test the "market size hypothesis" explicitly. In line with our theory, our strategy is to construct an industry specific exogenous variation in market size that allows to separate the market size

\footnotetext{
${ }^{1}$ Acemoglu and Linn (2004) is a notable exception showing evidence for a causal link between market size and innovation within the U.S. pharmaceutical industry.
} 
effect from the (potentially counter-acting) substitution effect. More specifically, we instrument the industrial market size by structural change at the final output level. We use the input-output relationship of the U.S. economy (similar to Herrendorf, Rogerson and Valentinyi, 2009) in order to determine how shifts on the final output level affect the industrial value-added structure. The identifying assumption of this IV approach is that an individual firm - which makes its R\&D investment decision takes variations in the potential industrial market size, caused by aggregate demand shifts, as exogenously given. ${ }^{2}$ Our results suggest that there is indeed a positive market size effect and TFP growth tends to increase in industries which inherently gain from the structural change on the level of final consumption goods.

The rest of the paper is organized as follows: The next section gives a motivating example of structural change and directed technical change, before Section 3 proceeds with the theoretical model. Our empirical test for the market size effect is provided in Section 4. Finally, Section 5 concludes.

\section{Motivating Example}

We motivate this paper's main mechanism with U.S. data of the durable and nondurable good sector. Figure 1 plots the total nominal expenditures on non-durable goods relative to total expenditures on durables on a logarithmic scale. Apart from the volatility due to recessions and World War II, the series has a strong negative trend (see dashed line). The annual growth rate of non-durable goods expenditures is on average 1.32 percentage points lower than the one of durable goods.

The corresponding price of non-durable relative to durable consumption goods is plotted in Figure 2. On a logarithmic scale, this series is clearly nonlinear, high-

\footnotetext{
${ }^{2}$ Note that in contrast to Acemoglu and Linn (2004), our strategy enables us to evaluate the market size hypothesis across the complete set of U.S. industries.
} 
lighting that the growth rate of the relative price is systematically changing over time. ${ }^{3}$ The growth rate of the relative price of non-durables (i.e., the slope of the series in Figure 2) increases continuously, being slightly negative in the thirties and clearly positive around 2012. A quadratic fit to the relative price series (see dashed line) suggests that the annualized growth rate of the relative price increases each year by about 0.048 percentage points. While it was minus 0.74 percent in 1930, it is plus 3.18 percent in 2012. As long-run dynamics in relative sectoral prices are typically explained by differences in sector specific total factor productivity (TFP) growth rates, the convex relative price path (on a logarithmic scale) depicted in Figure 2 indicates a huge shift in the direction of technical progress. This view is confirmed by Figure 3 which displays the decreasing time trend of the relative TFP growth rate of the non-durable compared to the durable sector. Consequently, explaining the relative price path depicted in Figure 2 requires a theory of sector specific endogenous growth.

Combining Figures 1 and 2 demonstrates that a theory of structural change that relies solely on substitution effects is insufficient to explain the data. First, the fact that nominal expenditures of the durable sector - whose relative price decreases - expand faster requires the elasticity of substitution to be larger than unity. In the structural change literature this case is regarded as empirically less relevant. Second, although the relative price barely changed over the first thirty years of the observed period, structural change is present even then. These two facts require a theory which allows for non-homothetic preferences and thus includes income effects

\footnotetext{
${ }^{3}$ The patterns outlined in Figure 1 and 2 are not an artifact of focusing on nominal personal consumption expenditures. The facts are unchanged when plotting total output of the durable and non-durable sector (see Figure C.1 in Online Appendix C). In addition, Figure C.2 in Online Appendix $\mathrm{C}$ shows that the non-durable good sector is also expanding in real terms at a slower rate than the durable good sector.
} 


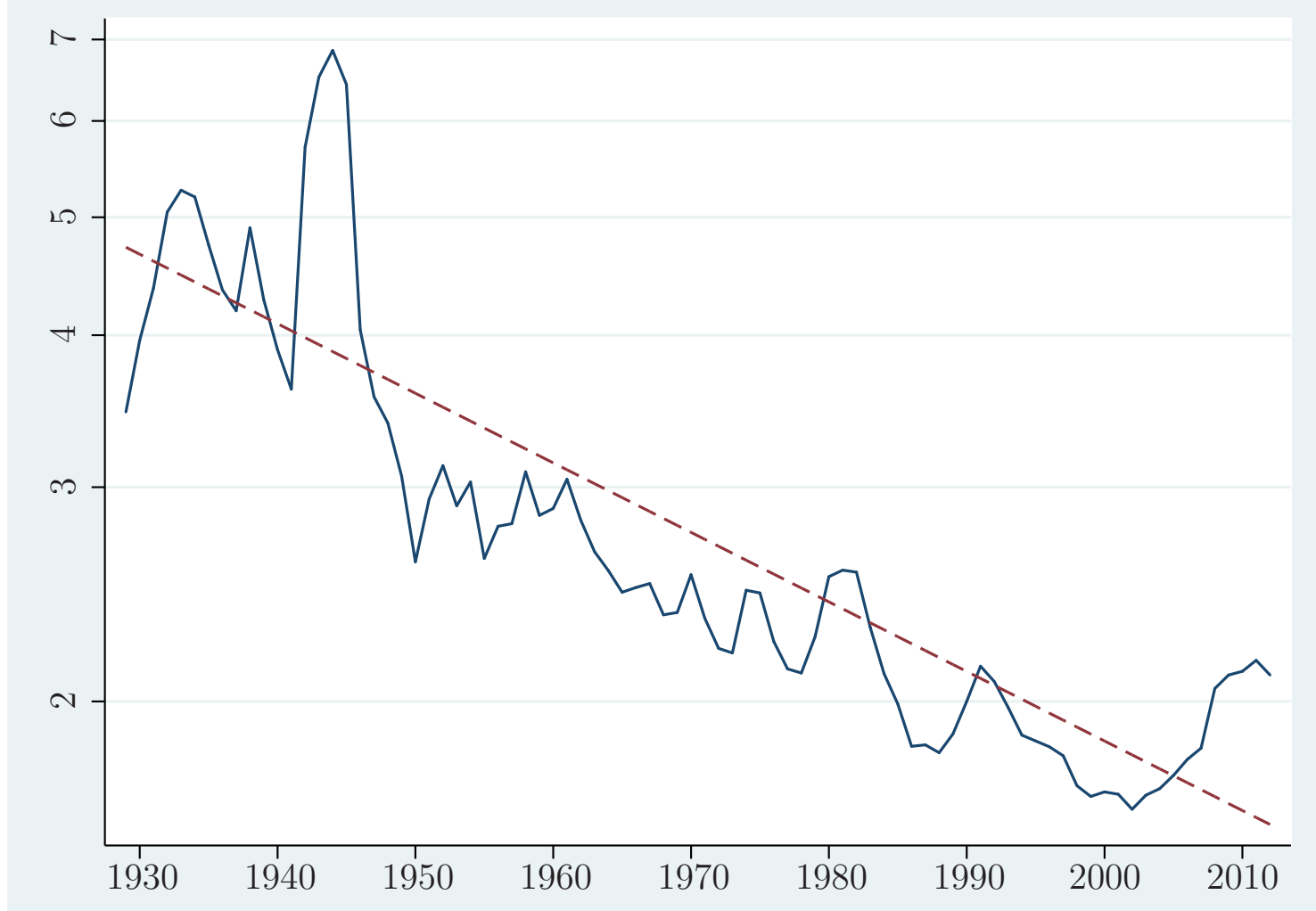

Figure 1: Nominal personal consumption expenditures on non-durables relative to expenditures on durables

Notes: The figure plots the nominal personal consumption expenditures devoted to non-durable goods relative to the one devoted to durable goods in the U.S. for 1929-2012 on a logarithmic scale. If we regress the logarithm of the relative expenditures on a constant and the year, the slope coefficient is -0.01316 with a standard error of 0.00078 .

Source: BEA, NIPA table 2.4.5. 


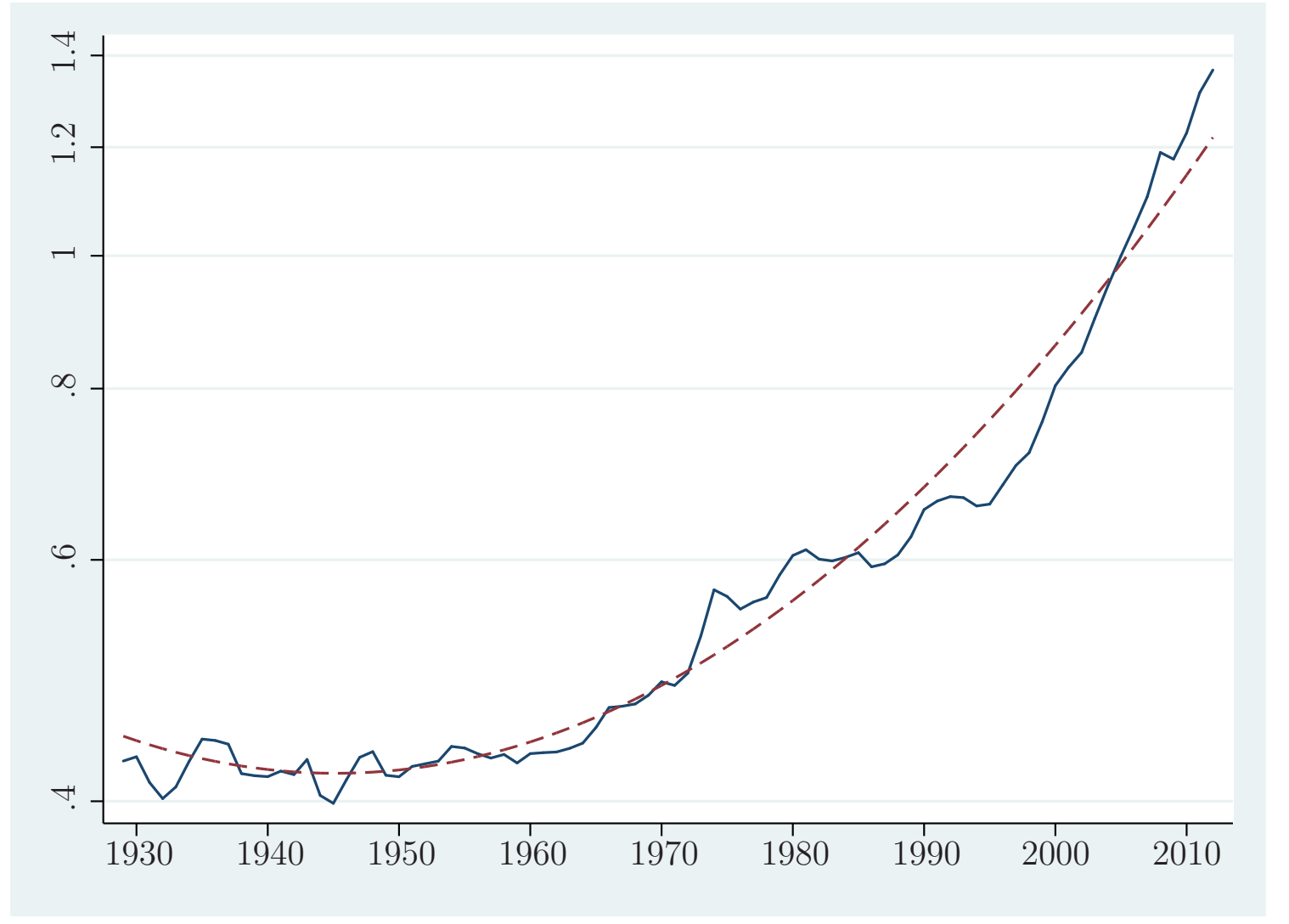

Figure 2: Relative consumer price index of non-durables relative to durables

Notes: The figure plots the relative price between non-durables and durables in the U.S. for 1929-2012 on a logarithmic scale. If we regress the logarithm of the relative price on a constant and the year in level and squared, the slope coefficients are -0.92990 and 0.00024 respectively (with standard errors of 0.04609 and 0.00001 ). The relative price is normalized to one in the year 2005 . Source: BEA, NIPA table 2.4.4. 


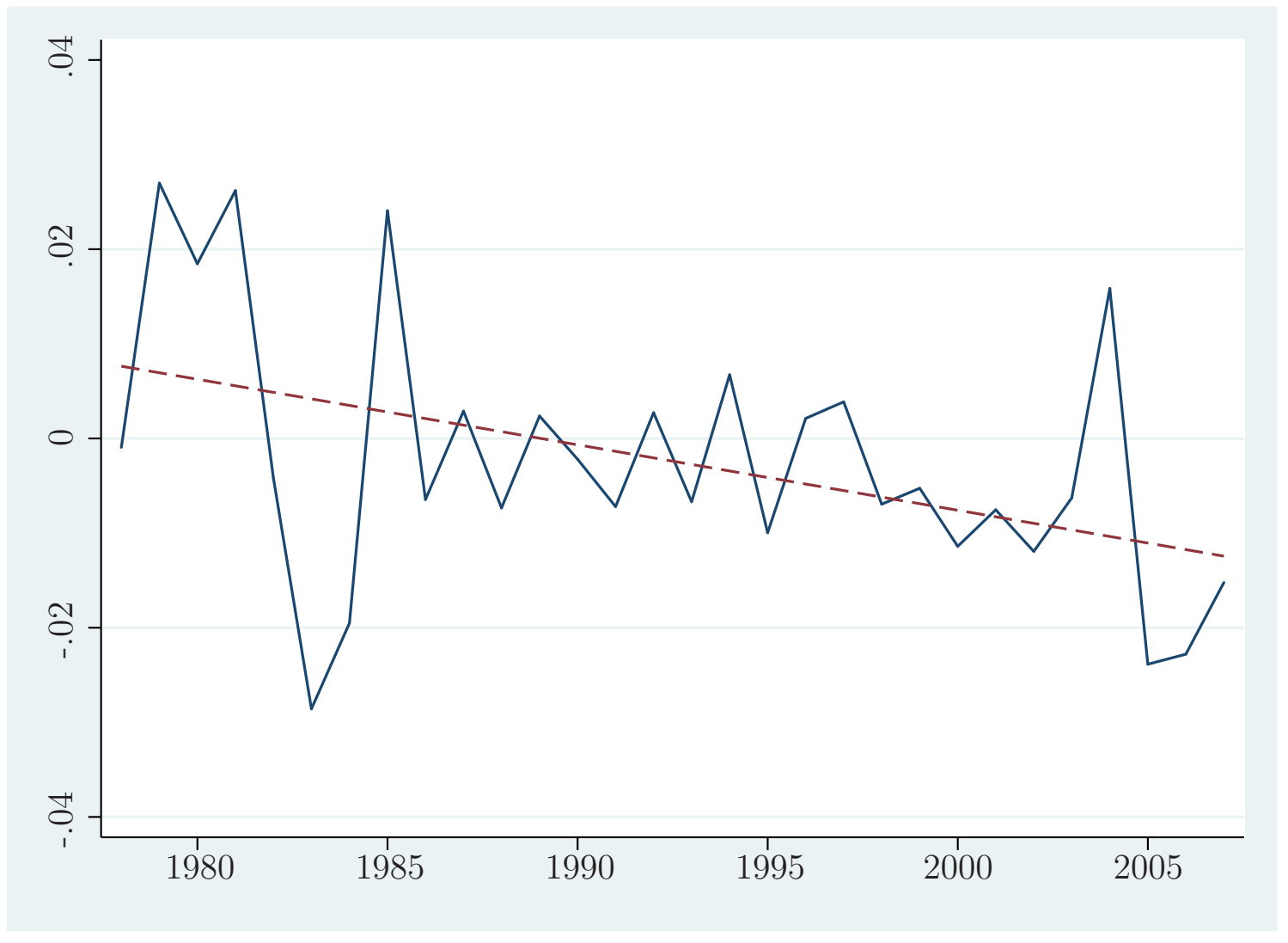

Figure 3: Difference between TFP growth rates of non-durables and

\section{durables}

Notes: The figure plots the difference between the rate of TFP growth of non-durables and the TFP growth rate of durables for the years 1978-2007 using input coefficients from I-O tables as weights. The slope of the fitted line is given by -0.00069 with a standard error of 0.00027 . The information of input-output tables is used to calculate the value-added industry weights of final nondurable/durable consumption. Then, the calculated TFP growth rate in terms of final consumption is the weighted average of the industries' value-added TFP growth (where the weights are these input-output coefficients). For more details see Online Appendix B.

Source: EU KLEMS; BEA, NIPA table 2.4.5, own calculation. 
as an additional driver of structural change. ${ }^{4}$ Moreover, the sweeping change in the expenditure structure (see Figure 1), which persists for more than eight decades, calls for a theory in which structural change is a long-run phenomenon.

Motivated by this illustrative example, we proceed to present our theoretical model.

\section{Theoretical model}

\subsection{Terminology of "sectors" and "industries"}

We develop a theory of directed technical change, where structural change is driven by both an income and a relative price effect. Preferences are specified over two final consumption goods. A luxury good with an expenditure elasticity of demand larger than unity, called the "durable" and a necessary good with an expenditure elasticity of demand strictly smaller than unity, called "non-durable". The durable and non-durable goods are the two sectors. Both final goods are produced using the same set of intermediate inputs, which consists of different industries $i \in[0,1]$. And the production processes of the two final consumption goods differ in their intensities with which they rely on a specific industry $i$.

\footnotetext{
${ }^{4}$ Especially, in the context of durable and non-durable goods the importance of income effects are incontestable as food expenditures account for 48.1 percent of non-durable expenditures in the year 1929 and Engel's law is regarded as one of the most robust empirical findings in economics (see Engel 1857, Houthakker, 1957 and Browning, 2008). This view is confirmed by Figure C.4 in Online Appendix C, which plots the fraction of goods expenditures devoted to durables for each income quartile of the U.S. on a logarithmic scale. Richer household devote a systematically larger fraction of their goods expenditures to durable goods.
} 


\subsection{Production}

\subsubsection{Production of the final good in the two sectors}

Both durable and non-durable goods are produced competitively with Cobb-Douglas technologies defined over the same unit interval of intermediate inputs, $\left\{x_{i}(t)\right\}_{i=0}^{1}$,

$$
Y_{D}(t)=\exp \left[\int_{0}^{1} \log \left[x_{i}(t)\right] d i\right]
$$

and

$$
Y_{N}(t)=\exp [\Delta t] \exp \left[\int_{0}^{1} \alpha(i) \log \left[x_{i}(t)\right] d i\right] B .
$$

The term $\Delta \gtreqless 0$ captures (potential) exogenous differences in the relative sectorspecific productivity growth rate and $B$ is a normalizing constant

$$
B=\exp \left[-\int_{0}^{1} \alpha(i) \log [\alpha(i)] d i\right] .
$$

Production of both final goods relies on the same set of intermediate inputs. However, the two sectors use them with different intensities. While the output elasticity of intermediate input $x_{i}(t)$ is unity in the durable good sector, it is $\alpha(i) \geq 0$ in the non-durable sector. We have $\int_{0}^{1} \alpha(i) d i=1$ and we denote the variance of the $\alpha(i)$ 's by $\sigma^{2} \geq 0$, i.e. $\sigma^{2} \equiv \int_{0}^{1} \alpha(i)^{2} d i-1$. If $\sigma^{2}=0$, the weights of the intermediate inputs are exactly the same for both final good sectors. In contrast, the larger $\sigma^{2}$, the more intensities differ across the two sectors.

Since final output markets are competitive the prices will be equal to the marginal cost. We set the durable good as the numéraire, i.e., we have

$$
1=\exp \left[\int_{0}^{1} \log \left[p_{i}(t)\right] d i\right]
$$

and the (relative) price of the non-durable good is given by

$$
P_{N}(t)=\exp \left[-\Delta t+\int_{0}^{1}(\alpha(i)-1) \log \left[p_{i}(t)\right] d i\right]
$$


where $p_{i}(t)$ is the price of intermediate industry input $i .^{5}$ The relative price between non-durable and durable goods, $P_{N}(t)$, changes for two reason. First, if $\Delta \neq 0$, there is an exogenous difference in the productivity growth rates which leads to a trend in relative prices. Second, as long as the two sectors use industries $i \in[0,1]$ with different intensities, i.e., $\sigma^{2} \neq 0$, dynamics in intermediate industry prices $p_{i}(t)$ also affect $P_{N}(t)$.

In the following we explain industry specific price changes by endogenous technical progress at the intermediate industry level.

\subsubsection{Production of intermediate inputs}

The intermediate inputs are produced competitively according to a standard "labequipment model" (see e.g. Acemoglu, 2009),

$$
y_{i}(t)=\frac{\nu}{\nu-1}\left[\int_{0}^{M_{i}(t)} \chi\left(\omega_{i}, t\right)^{\frac{\nu-1}{\nu}} d \omega_{i}\right] L_{i}(t)^{\frac{1}{\nu}}
$$

where $\nu>1 . L_{i}(t)$ denotes labor used in intermediate input production of industry $i$. Labor is fully mobile across sectors and earns a wage rate $w(t) . \quad \chi\left(\omega_{i}, t\right)$ is the amount of "machines" of variety $\omega_{i}$ that is used in the production of intermediate $i$. At a given date $t, M_{i}(t)$ denotes the number of different available machine varieties. The marginal costs of a machine $\chi\left(\omega_{i}, t\right)$ are $\psi_{i}(t)=\frac{\nu-1}{\nu} p_{i}(t)$, i.e. $\frac{\nu-1}{\nu}$ units of intermediate input $y_{i}(t)$. Each machine producer acts as a monopolist. Under these assumptions, firms' optimization implies the results that are summarized in the following lemma.

Lemma 1. Each machine producer sets its price at each point in time equal to

$$
p\left(\omega_{i}, t\right)=\frac{\nu}{\nu-1} \psi_{i}(t)=p_{i}(t), \forall \omega_{i}
$$

\footnotetext{
${ }^{5}$ The righthand sides of (1) and (2) represent the unit cost of the corresponding production functions in terms of the numéraire.
} 
Cost minimization and perfect competition at the intermediate industry level implies

$$
\chi\left(\omega_{i}, t\right)=L_{i}(t), \forall \omega_{i}
$$

and

$$
p_{i}(t)=(\nu-1) \frac{w(t)}{M_{i}(t)}, \forall i,
$$

where $w$ is the wage rate. Then, at a given point in time, each monopolist $\omega_{i}$ earns a profit flow of

$$
\pi\left(\omega_{i}, t\right)=\frac{\nu-1}{\nu} \frac{w(t) L_{i}(t)}{M_{i}(t)}, \forall \omega_{i} .
$$

The total amount of produced intermediate inputs $i$ can be expressed as

$$
y_{i}(t)=\frac{\nu}{\nu-1} M_{i}(t) L_{i}(t)
$$

The total amount of intermediate inputs $i$ used to produce machines $\omega_{i}$ is

$$
c_{i}(t)=\frac{\nu-1}{\nu} M_{i}(t) L_{i}(t)
$$

Proof. Since the market of intermediates is competitive, the representative firm solves

$$
\min _{\chi\left(\omega_{i}, t\right), L_{i}(t)} \int_{0}^{M_{i}(t)} p\left(\omega_{i}, t\right) \chi\left(\omega_{i}, t\right) d \omega_{i}+L_{i}(t) w(t),
$$

subject to (3) and a given output level $y_{i}(t)$. Calling the multiplier of constraint (3) $p_{i}(t)$ the first order conditions are,

$$
\begin{gathered}
p\left(\omega_{i}, t\right)=\chi\left(\omega_{i}, t\right)^{-\frac{1}{\nu}} L_{i}(t)^{\frac{1}{\nu}} p_{i}(t), \forall \omega_{i}, \\
w(t)=\frac{1}{\nu-1}\left[\int_{0}^{M_{i}(t)} \chi\left(\omega_{i}, t\right)^{\frac{\nu-1}{\nu}} d \omega_{i}\right] L_{i}(t)^{\frac{-\nu+1}{\nu}} p_{i}(t) .
\end{gathered}
$$

Due to the iso-elastic demand (11) it is optimal for the monopolist to set the price equal to $\frac{\nu}{\nu-1}$ times her marginal cost, $\psi_{i}(t)$, resulting in (4). Substituting this optimal price into (11) gives (5). Using this in (12) yields (6). Profit flows are given by quantity times the mark-up, i.e. $\pi\left(\omega_{i}, t\right)=\chi\left(\omega_{i}, t\right)\left[p\left(\omega_{i}, t\right)-\psi_{i}(t)\right]$. With 
(4)-(6) this reduces to (7). Using (5) in (3) yields (8). Finally, the total amount of machines used in industry $i$ is given by $\int_{0}^{M_{i}(t)} \chi\left(\omega_{i}, t\right) d \omega_{i}=M_{i}(t) L_{i}(t)$. Since each of these machines causes variable cost of $\frac{\nu-1}{\nu}$ units of intermediate input $y_{i}(t)$, the total number of intermediate inputs used to produce machines is given by (9).

So far the number of available machine varieties, $M_{i}(t)$, has been treated as exogenous. As a next step we specify how a new machine variety can be introduced.

\subsubsection{Production possibilities frontier}

By spending $\frac{1}{\eta}$ units of output of industry $i$ as R\&D investments, a new machine variety $\chi\left(\omega_{i}, t\right)$ can be invented. Hence, we have

$$
\dot{M}_{i}(t)=\eta z_{i}(t)
$$

where $z_{i}(t)$ denotes intermediate inputs of type $i$ used for R\&D investments (in industry $i$ ). There is free entry into research and a successful innovator obtains a perpetual patent on a machine variety $\omega_{i} . M_{i}(0), \forall i$ is exogenously given and we assume $M_{i}(0)=1, \forall i{ }^{6}$ Considering a situation with positive $\mathrm{R} \& \mathrm{D}$ investments in all industries $i$, we obtain the following Lemma.

Lemma 2. With positive R\&DD investments, the value of a machine producing firm is given by

$$
v\left(\omega_{i}, t\right)=v_{i}(t)=\frac{w(t)(\nu-1)}{\eta M_{i}(t)}, \forall \omega_{i} .
$$

Moreover, we must have

$$
r(t)-\frac{\dot{w}(t)}{w(t)}+\frac{\dot{M}_{i}(t)}{M_{i}(t)}=\frac{\eta L_{i}(t)}{\nu}, \forall i
$$

\footnotetext{
${ }^{6}$ This assumption is not crucial, but simplifies the analysis. Basically, as we will see below, it normalizes all relative prices between any two intermediate inputs to one at $t=0$.
} 
Proof. (14) highlights the fact that at each point in time, the value of a firm must be equal to the $R \& D$ cost of creating a new one, $\frac{p_{i}(t)}{\eta}$, where we substitute $p_{i}(t)$ by $(6)$. (15) is just the Hamilton-Jacobi-Bellman (HJB) representation of the zero ex-ante profit condition, i.e. $r(t) v_{i}(t)-\dot{v}_{i}(t)=\pi_{i}(t)$, where we make use of (14).

In order to close the model we need to specify the demand side of the economy. As motivated in Section 2 this demand side has to allow for non-homothetic preferences.

\subsection{Demand side}

Suppose we have a unit interval of identical households endowed with $L$ units of inelastically supplied labor and $A(0)$ units of (initial) wealth. Each household has the following preferences

$$
\mathcal{U}(0)=\int_{0}^{\infty} \exp (-\rho t)\left[\frac{1}{\epsilon} E(t)^{\epsilon}-\frac{\beta}{\gamma} P_{N}(t)^{\gamma}-\frac{1}{\epsilon}+\frac{\beta}{\gamma}\right] d t
$$

where $\rho>0$ is the rate of time preferences and the term in squared brackets is the indirect instantaneous utility function. This instantaneous utility function is defined over the nominal expenditure level, $E(t)$, and the prices of durables and non-durables. But as we have chosen the price of durables as our numéraire, only the (relative) price of non-durables, $P_{N}(t)$, shows up in (16). We have $0<\epsilon<1, \gamma \leq \epsilon$ and $\beta>0$. The intratemporal preferences are identical to Boppart (2011) and are a subclass of "price independent generally linearity" (PIGL) preferences specified in Muellbauer (1975) and Muellbauer (1976). ${ }^{7}$ The virtue of these preferences is that, although they are non-homothetic (and moreover do not fall into the Gorman class), the analysis of intertemporal optimization is very tractable.

\footnotetext{
${ }^{7}$ For more detail on these preferences, the reader is referred to Boppart (2011), where it is shown that these preferences remain very tractable even if we allow for household heterogeneity and population growth. However, note that the parameter space is slightly different compared to Boppart (2011) in order to allow for cases where the elasticity of substitution exceeds unity.
} 
The intratemporal preferences are only well defined if the expenditure level exceeds a certain threshold. In order to ensure this, we assume henceforth

$$
E(t)^{\epsilon} \geq \beta P_{N}(t)^{\gamma} .
$$

This condition will be fulfilled as long as the factor endowments $L$ and $A(0)$ are "sufficiently large". A condition in terms of exogenous model parameters which guarantees (17) is stated later on. Total consumption expenditures, $E(t)$, are spent on durables, $X_{D}(t)$ and non-durables, $X_{N}(t)$. Applying Roy's identity yields the following demand system:

Lemma 3. Intratemporal optimization implies

$$
\begin{array}{r}
X_{D}(t)=E(t)-\beta E(t)^{1-\epsilon} P_{N}(t)^{\gamma}, \\
X_{N}(t)=\beta E(t)^{1-\epsilon} P_{N}(t)^{\gamma-1},
\end{array}
$$

at each date in time.

We see that the demands are non-linear functions of the expenditure level $E(t)$. Hence, we have non-homothetic preferences. ${ }^{8}$ Condition (17) ensures the consumed quantities to be non-negative. The expenditure share devoted to non-durables, $S_{N}(t) \equiv \frac{P_{N}(t) X_{N}(t)}{E(t)}$, can be written as

$$
S_{N}(t)=\beta E(t)^{-\epsilon} P_{N}(t)^{\gamma}
$$

Clearly, $S_{N}(t)$ is declining in $E(t)$ and Engel's law applies. ${ }^{9}$ The expenditure elasticity of demand and the elasticity of substitution are the two elasticities that control

\footnotetext{
${ }^{8}$ The class of preferences (16) does enclose a homothetic case with $\epsilon \rightarrow 0$. But in this paper we focus on the more interesting non-homothetic cases with $\epsilon>0$.

${ }^{9}$ Interestingly, it is even consistent with the functional form Ernst Engel had in mind while studying the expenditure structure of Belgian workers. See Engel (1857), p. 30: "Das Gesetz, mit welchem man es hier zu thun hat, ist kein einfaches. Die Höhe der Ausgaben für Nahrung wachsen bei Abnahme des Wohlstandes in einer geometrischen Progression."
} 
the effects of changes in expenditure levels and relative prices on the demand structure. The expenditure elasticity of demand for non-durables is equal to $1-\epsilon$, which is strictly smaller than unity. Moreover, the elasticity of substitution is given by $1-\gamma+(\epsilon-\gamma) \frac{S_{N}(t)}{1-S_{N}(t)}$. So the elasticity of substitution is in general time varying and can be either larger or smaller than unity, depending on the parameter $\gamma \cdot{ }^{10}$ Overall, this means that both the income and substitution channel of structural change are present in the model and their importance is controlled by the parameters $\epsilon$ and $\gamma$. Next, we turn to the household's intertemporal optimization problem. The household takes the interest rate, $r(t)$, and wage rate, $w(t)$, as given and maximizes (16) subject to the flow budget constraint and the transversality condition, which read

$$
\dot{A}(t)=r(t) A(t)+w(t) L-E(t) \text { and } \lim _{t \rightarrow \infty} E(t)^{\epsilon-1} A(t) \exp [-\rho t]=0 .
$$

This yields the following Lemma:

Lemma 4. Intertemporal optimization implies the following Euler equation

$$
(1-\epsilon) \frac{\dot{E}(t)}{E(t)}=r(t)-\rho .
$$

Proof. The current Hamiltonian reads

$$
\mathcal{H}=V\left(E(t), P_{N}(t)\right)+\lambda(t)[r(t) A(t)+w(t) L-E(t)] .
$$

We can write the first-order conditions as

$$
\begin{array}{r}
E(t)^{\epsilon-1}-\lambda(t)=0, \\
r(t) \lambda(t)=\rho \lambda(t)-\dot{\lambda}(t) .
\end{array}
$$

Taking the first derivative of (23) with respect to time and simplifying gives (22).

\footnotetext{
${ }^{10} \mathrm{As}$ it will be shown later on, we have $\lim _{t \rightarrow \infty} S_{N}(t)=0$, so $1-\gamma$ can be interpreted as the asymptotic elasticity of substitution.
} 
This is the familiar form of the Euler equation which is consistent with a constant growth path along which the saving and interest rate are constant. Note that we obtain this simple Euler equation although intratemporal preferences are non-homothetic.

\subsection{Market clearing and resource constraints}

Market clearing at the final output sector level implies

$$
Y_{j}(t)=X_{j}(t), j=\{D, N\}
$$

On the industry level, market clearing requires

$$
y_{i}(t)=\tilde{x}_{i}(t)+c_{i}(t)+z_{i}(t), \forall i \in[0,1]
$$

where $y_{i}(t)$ is total production of intermediate inputs. $\tilde{x}_{i}(t)$ is the total amount of intermediate inputs used in final goods production. $c_{i}(t)$ are total intermediate inputs used to produce machines and $z_{i}(t)$ are total intermediate inputs used as R\&D investments. Labor market clearing can be written as

$$
L=\int_{0}^{1} L_{i}(t) d i
$$

Finally, asset market clearing implies

$$
A(t)=\int_{0}^{1} M_{i}(t) v_{i}(t) d i
$$

\subsection{Dynamic equilibrium}

In this economy, a dynamic equilibrium is defined as follows:

Definition 1. A dynamic equilibrium is a time path of expenditure, wealth and consumption quantities $\left\{E(t), A(t), X_{N}(t), X_{D}(t)\right\}_{t=0}^{\infty}$, prices, wage rate and interest rate $\left\{P_{N}(t), w(t), r(t)\right\}_{t=0}^{\infty}$, available machine varieties, output, labor demand, R\&D 
investment and price in each industry $\left\{M_{i}(t), y_{i}(t), L_{i}(t), z_{i}(t), p_{i}(t)\right\}_{t=0}^{\infty}, i \in[0,1]$, and quantity and price of all machines varieties in all industries $\left\{\chi\left(\omega_{i}, t\right), p\left(\omega_{i}, t\right)\right\}_{t=0}^{\infty}$, $\forall \omega_{i}, i \in[0,1]$ which are jointly consistent with household and firm optimization, the resource constraint and market clearing, given the specified market structure (i.e. perfect competition in all markets with the exception of the machine producers who have a monopoly position).

Before solving the model, we briefly relate the specified framework to some reference cases. First, with $\beta=0$, the representative household only consumes good $D$ (i.e. durables). In this case, the perfectly symmetric unit interval of intermediate inputs becomes obsolete and the economy coincides with the standard one-sector lab-equipment model where households have CRRA preferences (see e.g. Acemoglu, 2009, chapter 13). Second, with $\epsilon \rightarrow 0, \sigma^{2}=0$ and $\Delta \neq 0$, we have homothetic preferences and identical technologies across sectors - with the exception of a Hicksneutral exogenous but sector specific TFP growth rate. In this case, the model is very similar to Ngai and Pissarides (2007). The equilibrium dynamics feature structural change due to relative price effects and we can solve the model explicitly since the Kaldor facts will be fulfilled. ${ }^{11}$ However, such an analysis clearly abstracts from biased technical change and there would be no income effects on the demand structure. Third, with $\epsilon \neq 0, \sigma^{2}=0$ and $\Delta \neq 0$, the model becomes similar to Boppart (2011) where structural change is driven by the non-homotheticity of preferences. But since $\sigma^{2}=0$ structural change at the sector level does not trickle down to intermediary inputs and hence does not induce directed technical change on the industry level. Finally, if we consider homothetic preferences (i.e. $\epsilon \rightarrow$ 0 ), introduce two different types of labor (skilled and unskilled), and assume that

\footnotetext{
${ }^{11}$ The reason why the model would not be identical to Ngai and Pissarides (2007) is due to the fact that they use a CES utility function, whereas in our model the elasticity of substitution between durables and non-durables is not constant over time.
} 
different intermediate industries use these two labor types with different intensities, we move towards a standard model of directed technical change à la Acemoglu (1998).

It is important to emphasize that none of the aforementioned models contain all the characteristics motivated in Section 2. In the next subsection we solve our model and show that it features industry directed technical change while the long-run structural change is driven by both an income and a substitution effect.

\subsection{Solving for the dynamic equilibrium path}

\subsubsection{Aggregate dynamics}

We solve the model in two parts: First, we show that the dynamic equilibrium path features standard balanced properties on the aggregate (i.e. the Kaldor facts are fulfilled). Second, we characterize the sectoral dynamics. This is more complicated since we have to deal with relatively rich dynamics at the disaggregate level. But irrespectively of these sectoral dynamics, the next proposition shows that on the aggregate the model has a unique dynamic path with a closed form solution.

Proposition 1. Suppose we have $\frac{\eta L}{\nu}>\rho>\frac{\epsilon \eta L}{\nu}$. Then, the model features no transitional dynamics and the real (durable good denominated) interest rate and the growth rates of wealth, wages and expenditures are constant, i.e.

$$
\begin{gathered}
r=\frac{\eta L}{\nu} \\
\frac{\dot{A}(t)}{A(t)}=\frac{\dot{w}(t)}{w(t)}=\int_{0}^{1} \frac{\dot{M}_{i}(t)}{M_{i}(t)} d i=\frac{\dot{E}(t)}{E(t)}=\frac{1}{1-\epsilon}\left[\frac{\eta L}{\nu}-\rho\right] \equiv g>0 .
\end{gathered}
$$

Moreover, we have

$$
w(t)=\frac{1}{\nu-1} \exp [g t],
$$

and

$$
E(0)=\left[\frac{L}{\nu-1}+\frac{1}{(1-\epsilon) \eta}\left[\rho-\frac{\epsilon \eta L}{\nu}\right]\right] \equiv \mathcal{E}_{0}>0
$$


This is an equilibrium path as long as (17) is fulfilled for all $t$.

Proof. The choice of numéraire $P_{D}(t)=1$ implies (see (1) and (6))

$$
1=(\nu-1) w(t) \exp \left[-\int_{0}^{1} \log \left[M_{i}(t)\right] d i\right] .
$$

By differentiating this with respect to time we get

$$
\int_{0}^{1} \frac{\dot{M}_{i}(t)}{M_{i}(t)} d i=\frac{\dot{w}(t)}{w(t)} .
$$

If we take the sum over all $i \in[0,1]$ of both sides of (15) and use the labor market clearing condition, (27), we get

$$
r(t)-\frac{\dot{w}(t)}{w(t)}+\int_{0}^{1} \frac{\dot{M}_{i}(t)}{M_{i}(t)} d i=\frac{\eta L}{\nu} .
$$

Combining (34) and (35) yields

$$
r(t)=r=\frac{\eta L}{\nu}
$$

This implies that in any equilibrium, the interest rate (in terms of durable goods) must be constant over time. With a constant interest rate the Euler equation, (22), implies a constant expenditure growth rate $\frac{\dot{E}(t)}{E(t)}=g$, where $g>0$ because $\frac{\eta L}{\nu}>\rho$. The asset market clearing condition, (28), together with (14) implies $\frac{\dot{A}(t)}{A(t)}=\frac{\dot{w}(t)}{w(t)}$. Finally, substituting this into the flow budget constraint, (21), implies $\frac{\dot{A}(t)}{A(t)}=g$. This proves (29) and (30). For (31) note that (33) and the assumption $M_{i}(0)=1$, $\forall i$ implies $w(0)=\frac{1}{\nu-1}$. Next, $c_{i}(t)$ and $y_{i}(t)$ are given by (9) and (8) and if we combine (13) and $(15)$ we get $z_{i}(t)=M_{i}(t)\left[\frac{L_{i}(t)-L}{\nu}+\frac{g}{\eta}\right]$. Plugging this into the market clearing condition, (26), implies

$$
\tilde{x}_{i}(t)=M_{i}(t)\left[\frac{L_{i}(t)}{\nu-1}+\frac{1}{\nu} L-\frac{g}{\eta}\right] .
$$

Finally we obtain total consumption expenditures $E(t)=\int_{0}^{1} p_{i}(t) \tilde{x}_{i}(t) d i$, where $p_{i}(t)$ is given by $(6) . \mathcal{E}_{0}$ is strictly positive since $\rho>\frac{\epsilon \eta L}{\nu}$. This assumption also ensures that the transversality condition is fulfilled and that utility is finite. 
Proposition 1 shows that the aggregate variables behave in the dynamic equilibrium as in the steady state of a neoclassical growth model and Kaldor's stylized facts (see Kaldor, 1961) are fulfilled. It is noteworthy that we can solve for the aggregate dynamics without knowing the exact equilibrium path of the disaggregate variables. This separation keeps the problem tractable and allows us to find a closed form characterization of the disaggregate dynamics, as we will show in the next step.

\subsubsection{Disaggregate dynamics}

The disaggregate equilibrium dynamics of this model are much richer than the aggregate, because the expenditure structure, $S_{N}(t)$, and the intermediate input prices, $\left\{p_{i}(t)\right\}_{i=0}^{1}$, interact with each other in two ways. On the one hand, the dynamics of intermediate input prices affect the (relative) price of non-durable goods, $P_{N}(t)$, and consequently via a standard substitution effect the demand structure $S_{N}(t)$. On the other hand, as in any theory of directed technical change, the demand structure determines the (industry specific) R\&D investment incentive and via this channel the dynamics of intermediate industry prices. Interestingly, the causality of the two effects go in different directions. The two effects are highlighted in the next lemma.

Lemma 5. The disaggregate dynamics can be summarized by the following equations:

$$
S_{N}(t)=\beta \mathcal{E}_{0}^{-\epsilon} \exp \left[-\epsilon g t-\gamma \Delta t+\gamma \int_{0}^{1}[\alpha(i)-1] \log \left[p_{i}(t)\right] d i\right]
$$

and

$$
p_{i}(t)=\exp \left[-\eta \frac{\nu-1}{\nu} \mathcal{E}_{0} \int_{0}^{t} S_{N}(\tau)[\alpha(i)-1] d \tau\right], \forall i,
$$

where expenditures at date zero, $\mathcal{E}_{0}$, and the growth rate, $g$, are defined in Proposition 1.

Proof. First, note that we can write $E(t)=\mathcal{E}_{0} \exp [g t]$ (see (30) and (32)). If we use this expression and (2) in (20), we obtain (37). 
Second, let us prove equation (38): Since the final consumption goods are produced competitively with Cobb-Douglas technologies (implying output elasticities of the durable and non-durable sector which are equal to unity and $\alpha(i))$, we must have $p_{i}(t) \tilde{x}_{i}(t)=E(t) S_{N}(t) \alpha(i)+E(t)\left[1-S_{N}(t)\right]$. If we substitute $p_{i}(t), \tilde{x}_{i}(t)$ in this equation by the expressions (6) and (36) and use the definition of $g$ and $\mathcal{E}_{0}$, we get

$$
(\nu-1) w(t)\left[\frac{L_{i}(t)-L}{\nu-1}+\mathcal{E}_{0}\right]=E(t) S_{N}(t) \alpha(i)+E(t)\left[1-S_{N}(t)\right] .
$$

If we additionally substitute $w(t)$ by $(31)$ and $E(t)$ by $\mathcal{E}_{0} \exp [g t]$ and simplify terms, we have

$$
L_{i}(t)-L=S_{N}(t)(\nu-1)[\alpha(i)-1] \mathcal{E}_{0}
$$

Now, if we use (29) and (30) in (15), we get

$$
\frac{\dot{M}_{i}(t)}{M_{i}(t)}=\frac{\eta\left[L_{i}(t)-L\right]}{\nu}+g
$$

Then, combining this with (6), (31) (and the fact that $M_{i}(0)=1, \forall i$ ) we can write

$$
p_{i}(t)=\exp \left[-\frac{\eta}{\nu} \int_{0}^{t}\left(L_{i}(\tau)-L\right) d \tau\right]
$$

If we substitute $L_{i}(\tau)-L$ in this expression by the analog of equation (39) we obtain equation (38).

(37) visualizes the substitution effect of intermediate industry prices on the demand structure, whereas (38) formalizes the directed technical change effect from the expenditure structure on the industry price dynamic.

The expenditure share of the non-durable sector, $S_{N}(t)$, changes over time for two reasons: First, households have non-homothetic preferences and (per-capita) expenditures grow along the dynamic equilibrium path with rate $g$. Since non-durables are necessities and durables luxuries, $S_{N}(t)$ tends to decline over time. The magnitude of this effect is governed by the degree of non-homotheticity of preferences, $\epsilon$, and the growth rate of (per-capita) expenditures, $g$. With homothetic preferences (i.e. 
$\epsilon=0)$ we would have no income effect on the demand structure and the corresponding term in (37) would vanish. The second reason why $S_{N}(t)$ changes over time is that the relative price $P_{N}(t)$ varies. Clearly, the relative price changes due to the exogenous difference in TFP growth rates, $\Delta$. But in addition, $P_{N}(t)$ varies since there are differences in the intensities with which the sectoral outputs depend on the different intermediate industries (represented by the $\alpha(i)$ 's) and since industry specific prices, $p_{i}(t)$, change according to directed technical progress. The sign and magnitude of this relative price effect on the demand structure is determined by the elasticity of substitution between the two sectors, which itself is controlled by the parameter $\gamma$. If the (asymptotic) elasticity of substitution between goods and services is unity (i.e. $\gamma=0$ ) the demand structure is independent of the relative price $P_{N}(t)$. If durables and non-durables are (asymptotically) gross substitutes (i.e. $\gamma<0$ ) the sector which experiences a relative price increase loses in terms of expenditure shares. With gross complements the opposite is true.

Equation (38) characterizes how endogenous technical change affects the price of intermediate industry $i$. In a given point in time $\tau$, the growth rate of the price of industry $i$ is given by the inverse of R\&D activity in this industry (relative to the average over all industries). More formally ${ }^{12}$,

$$
\frac{\dot{p}_{i}(\tau)}{p_{i}(\tau)}=g-\frac{\dot{M}_{i}(\tau)}{M_{i}(\tau)}
$$

Consequently, the price of industry $i$ at date $t$ is given by the history of R\&D activities up to date $t$. What determines the $R \& D$ activity in industry $i$ at a given date $\tau$ ? As equation (15) shows, this R\&D activity is positively related to the number of people employed in the industry. This is a standard market size effect indicating that the incentive to innovate a new machine increases proportionally to the number of workers that use it. The number of workers in industry $i$ is above

\footnotetext{
${ }^{12}$ This follows immediately from (6) and (31). The average of the R\&D activity over all industries shows up because of the choice of numéraire.
} 
average if the intensity, $\alpha(i)$, with which non-durable good production depends on it exceeds unity (see (39)). Moreover, given that industry $i$ is, as an input, more intensively used by the non-durable sector (i.e. $\alpha(i)>1$ ), the number of workers employed in this industry is increasing in the expenditure share of non-durables. Equations (37) and (38) define a system of equations in $S_{N}(t)$ and $\left\{p_{i}(t)\right\}_{i=0}^{1}$. By setting $t$ equal to zero, we obtain the initial conditions

$$
p_{i}(0)=1, \forall i
$$

and

$$
S_{N}(0)=\beta\left[\frac{L}{\nu-1}+\frac{1}{(1-\epsilon) \eta}\left[\rho-\frac{\epsilon \eta L}{\nu}\right]\right]^{-\epsilon}=\beta \mathcal{E}_{0}^{-\epsilon} .
$$

Solving the system of equations we obtain the following proposition:

Proposition 2. Along the dynamic equilibrium path, the sectoral dynamics are characterized by

$$
S_{N}(t)=\frac{S_{N}(0)}{\exp [(\gamma \Delta+\epsilon g) t]+[\exp [(\gamma \Delta+\epsilon g) t]-1] \frac{S_{N}(0) \gamma \eta \frac{\nu-1}{\nu} \sigma^{2} \mathcal{E}_{0}}{\gamma \Delta+\epsilon g}},
$$

where $S_{N}(0)$ is given by (42). Moreover, we have

$$
\begin{gathered}
P_{N}(t)=\exp \left[\frac{\epsilon g}{\gamma} t\right]\left(\frac{S_{N}(t)}{S_{N}(0)}\right)^{\frac{1}{\gamma}}, \\
L_{i}(t)=L+(\nu-1) \mathcal{E}_{0}[\alpha(i)-1] S_{N}(t),
\end{gathered}
$$

and

$$
p_{i}(t)=\left[\frac{S_{N}(t)}{S_{N}(0)} \exp [(\gamma \Delta+\epsilon g) t]\right]^{\frac{\alpha(i)-1}{\gamma \sigma^{2}}} .
$$

This is an equilibrium path under the parameter restrictions stated in Proposition 1 and as long as (17) is fulfilled for all $t$. 
Proof. Substituting $p_{i}(t)$ in (37) by (38) and using the fact that $\int_{0}^{1}[\alpha(i)-1]^{2} d i=$ $\sigma^{2}$

$$
S_{N}(t)=S_{N}(0) \exp \left[-\gamma \Delta t-\epsilon g t-\gamma \eta \frac{\nu-1}{\nu} \sigma^{2} \mathcal{E}_{0} \int_{0}^{t} S_{N}(\tau) d \tau\right] .
$$

Differentiating both sides of this equations with respect to time we obtain the following differential equation

$$
\frac{\dot{S}_{N}(t)}{S_{N}(t)}=-\gamma \Delta-\epsilon g-\gamma \eta \frac{\nu-1}{\nu} \sigma^{2} \mathcal{E}_{0} S_{N}(t) .
$$

By solving this differential equation we obtain (43). Once we have solved for this, (44)-(46) follow immediately from (20), (39) as well as (38) and (47).

Proposition 2 shows that we indeed obtain closed form solutions for all variables.

Finally, note that we assumed that (17) is fulfilled along the entire path. We are now prepared to state conditions on the exogenous parameters such that this condition is indeed met. This is done in the next proposition. Recall that condition (17) ensures that the expenditure share devoted to non-durables does not exceed unity. As we can see from (43), the dynamics of $S_{N}(t)$ depend on several parameter values. In the following we focus on a case in which the durable good sector is asymptotically dominant, for which we get:

Proposition 3. Suppose

$$
\begin{gathered}
\gamma \Delta+\frac{\epsilon}{1-\epsilon}\left[\frac{\eta L}{\nu}-\rho\right] \geq 0 \\
\gamma \Delta+\frac{\epsilon}{1-\epsilon}\left[\frac{\eta L}{\nu}-\rho\right]>-\gamma \eta \frac{\nu-1}{\nu} \sigma^{2} \beta\left[\frac{L}{\nu-1}+\frac{1}{(1-\epsilon) \eta}\left[\rho-\frac{\epsilon \eta L}{\nu}\right]\right]^{1-\epsilon},
\end{gathered}
$$

and

$$
\beta<\left[\frac{L}{\nu-1}+\frac{1}{(1-\epsilon) \eta}\left[\rho-\frac{\epsilon \eta L}{\nu}\right]\right]^{\epsilon} .
$$

Then, condition (17) is fulfilled along the entire path and the dynamics in Propositions 1 and 2 characterize a dynamic equilibrium path. 
Proof. (51) ensures that (17) is fulfilled at date $t=0$ (see (42)). Moreover, (49) and (50) ensure that $\frac{\dot{S}_{N}(t)}{S_{N}(t)}<0, \forall t \geq 0$ (see (48)). Hence, $S_{N}(0)$ is smaller or equal to one and it is falling over time. Consequently, (17) is fulfilled for all $t \geq 0$.

We are now ready to discuss the equilibrium dynamics on the disaggregate level. The assumptions in Proposition 3 make sure that $S_{N}(t)$ is declining over time. An easy way to see the dynamics of $S_{N}(t)$ is in equation (48). The non-homotheticity channel leads to a declining $S_{N}(t)$, since non-durables are necessities by assumption and expenditures grow over time. So the conditions in Proposition 3 ensure that this declining trend in $S_{N}(t)$ due to income effects is not overturned by a relative price effects. Whether the relative price effects increases or decreases $S_{N}(t)$ depends on the elasticity of substitution as well as on how $P_{N}(t)$ changes over time. If the (asymptotic) elasticity of substitution is larger than unity (i.e. if $\gamma<0$ ), an increase in the relative price, $P_{N}(t)$, decreases the expenditure share devoted to non-durables. With $\gamma>0$ the opposite is true. For the growth rate of the (relative) price of the non-durable sector, we obtain (see (44) and (48))

$$
\frac{\dot{P}_{N}(t)}{P_{N}(t)}=-\Delta-\eta \frac{\nu-1}{\nu} \sigma^{2} \mathcal{E}_{0} S_{N}(t) \text {. }
$$

The relative price changes because of the exogenous TFP growth rate difference, $\Delta$, as well as because of industry specific technical progress (captured by the second term in $(52))$.

With $\frac{\dot{S}_{N}(t)}{S_{N}(t)}$ being always negative the expenditure share of non-durable goods asymptotically converges to zero and the durable sector is therefore asymptotically dominant. ${ }^{13}$ As time goes to infinity, $\frac{\dot{S}_{N}(t)}{S_{N}(t)}$ converges to $-(\gamma \Delta+\epsilon g)$, which is still negative (see assumption (49)). In this sense, structural change does not come to a halt and does exist even asymptotically. In contrast, since asymptotically the di-

\footnotetext{
${ }^{13}$ Note that just the expenditure share of non-durables goes to zero. In levels non-durable good expenditures go to infinity.
} 
rection of industry specific technical change is fully determined by the durable good sector, we have

$$
\lim _{t \rightarrow \infty} \frac{\dot{P}_{N}(t)}{P_{N}(t)}=-\Delta
$$

Hence, asymptotically, the growth rate of the relative price does not change anymore (but it can differ from zero).

The theory offers relatively rich dynamics. It is worthwhile to emphasize that these dynamics occur along the equilibrium path of a dynamic general equilibrium model. Consequently there are no exogenous shifts in demand or supply. Since the (asymptotic) elasticity of substitution can be either larger or smaller then unity (i.e. $\gamma \lesseqgtr 0$ ) our theory does not take a stand whether the expenditure share, $S_{N}(t)$, increases or decreases in the relative price (see (20)). In addition, because there are both relative price and income effects on the expenditure structure, the elasticity of substitution between durables and non-durables is not so easy to infer. For instance, the fact that the expenditure share of non-durable goods declined whereas the relative price of non-durable goods increased over the last 80 years does not automatically imply that the elasticity of substitution has to be larger than unity. It could well be that it is strictly smaller than unity but the relative price effect on the expenditure structure is overturned by an income effect.

From (52) it is clear that our theory does not make a prediction about the average level of relative price growth (i.e. whether $P_{N}(t)$ is increasing or declining). Depending on the sign of $\Delta$ this can either be negative or positive. However, the theory does make a clear prediction how $\frac{\dot{P}_{N}(t)}{P_{N}(t)}$ changes over time: The growth rate of the (relative) price of a sector which experiences a decline in terms of its expenditure share increases over time. This is consistent with Figure 1 and 2. The reason for this dynamic is directed technical change. As the expenditure share of the non-durable sector shrinks, (45) shows that a declining amount of labor is allocated to industries which are relative intensively used by the non-durable sector (i.e. with $\alpha(i)>1$ ). 
A declining market size in these sectors imply a declining R\&D activity (see (40)) and an increasing industry specific price growth $\frac{\dot{p}_{i}(t)}{p_{i}(t)}$. This effect constitutes the so called market size effect. Formally, this can be seen from combining (46) and (48) and writing the industry specific price growth as

$$
\frac{\dot{p}_{i}(t)}{p_{i}(t)}=-[\alpha(i)-1] \eta \frac{\nu-1}{\nu} \mathcal{E}_{0} S_{N}(t) .
$$

As the price growth rate of industries that are more intensively used in the nondurable sector increases, the growth rate of the relative price of non-durables, $P_{N}(t)$, increases too. ${ }^{14}$

It is the aim of the next section to test this prediction of industry directed technical change using disaggregate U.S. data. By doing so we explicitly make use of the inputoutput structure of the U.S. economy. This allows us to identify the variation in the industrial market shares which is exogenous from the perspective of an individual firm that makes the decision of how much to invest in R\&D.

\section{Empirical Application}

\subsection{Testing for the market size effect}

In the following, we test for our theory's prediction how structural change in terms of final consumption translates into changes in the market sizes of different industries at the value-added level and how this in turns affects industry specific TFP and output price growth rates. We use U.S. data from EU KLEMS covering 30 different industries and 30 years. ${ }^{15}$ For our analysis we build five-year spells, which leads to 180 observations. Our model's main prediction suggest a negative (positive) correlation between an industry's market size and its price (TFP) growth rate. This

\footnotetext{
${ }^{14}$ For this see $(2)$, which implies that we have $\frac{\dot{P}_{N}(t)}{P_{N}(t)}=-\Delta+\int_{0}^{1}(\alpha(i)-1) \frac{\dot{p}_{i}(t)}{p_{i}(t)} d i$.

${ }^{15} \mathrm{~A}$ precise list of data sources can be found in Online Appendix B.
} 
motivates the following regression

$$
d_{i}(t)=\delta \log s_{i}(t-l)+\kappa_{i}+\phi(t)+u_{i}(t)
$$

where $d_{i}(t)$ is one of the dependent variables (i.e. either the TFP or the price growth rate). $s_{i}(t-l)$ is the market size of industry $i, \kappa_{i}$ and $\phi(t)$ represent a full set of industry and time fixed effects and $u_{i}(t)$ is an error term. The TFP and price growth rates, $d_{i}(t)$, are calculated as log-differences over the five-year interval between $t$ and $t-5$. The market size measures the average fraction of industry value-added, $v a_{i}$, relative to total GDP over a five-year interval, or formally ${ }^{16}$

$$
s_{i}(t-l)=\frac{1}{5} \sum_{k=1}^{5} \frac{v a_{i}(t-l-k)}{G D P(t-l-k)} .
$$

An important question is the timing. In our theory, where all agents are perfectly forward looking and $R \& D$ investments immediately result in a TFP enhancing innovation, expenditure shares and TFP growth rates co-move instantaneously. Arguably, this is not true in reality and for this reason we explore different time lags of length of zero, one and two periods (i.e. $l=0,5,10)$. The industry and time fixed effects are included to control for industry specific differences in the effectiveness of $\mathrm{R} \& \mathrm{D}$ investments and time trends in the average productivity growth rate. ${ }^{17}$ Our theory of directed technical change makes a prediction about the sign of $\delta$ and this is the parameter of main interest.

Table 1 presents results of our baseline specification using the industry specific price growth rate as a dependent variable. The contemporaneous logarithmized valueadded share shows no significant correlation with the current rate of price growth, which is displayed in column (1). However, if we take lagged market shares we see

\footnotetext{
${ }^{16}$ Note that this allows us to interpret it directly as an industry's market share. Both terms market size and market share will be used interchangeably in the following.

${ }^{17}$ Note again that our theory's main prediction is about changes in industry specific TFP and price growth rates and not their levels.
} 
a negative correlation with the price growth rate (see columns (2) and (3) in Table 1). This finding might have two different interpretations. On the one hand, the evolution of market shares might not perfectly be foreseen and R\&D investments might take some time to materialize. This suggests that the correlation between an industry's market size and price growth rate is zero contemporaneously, becomes negative after some years and finally attenuates again. In Online Appendix A, we show for a subset of years and industries for which we have a measure of the R\&D stock, that the growth rate of the $R \& D$ stock reacts immediately (and that there is no anticipating effect). This is in line with the found lags of the effects on prices (and TFP later on).

On the other hand, the low and insignificant coefficient in column (1) could also be the result of reversed causality. Suppose the industry specific price fluctuates for exogenous reasons. Then, if the short run elasticity of substitution is smaller than one, periods with high prices are correlated with high value-added shares. This mechanical effect runs in the opposite direction of the market size effect of induced innovation and attenuates the estimate for $\delta$. One way to relax this problem is to use the lagged value-added share. In column (4) we include both the contemporaneous and the lagged market share and show that the coefficient of the lagged market share remains significant. This mitigates the concern that the coefficient in column (2) is driven by the mechanical contemporaneous effect as well as a serial correlation in the independent variable.

The magnitude of the estimated effect of column (2) suggests that a one percent increase in an industry's market share relative to GDP decreases the price growth rate by 0.52 percentage points over the next five years. Given the standard deviation of this variable of 21 percentage points, this is an economically significant effect.

Since there exists a strong negative correlation between the industry specific TFP growth rates and the relative price changes, it is not surprising to find the analog 
Dependent variable: Price growth rate

\begin{tabular}{lcccc}
\hline \hline & $(1)$ & $(2)$ & $(3)$ & $(4)$ \\
\hline Log market share & 0.026 & & & $0.847^{* *}$ \\
& $(0.088)$ & & & $(0.374)$ \\
L.Log market share & & $-0.522^{* * *}$ & & $-1.081^{* * *}$ \\
& & $(0.202)$ & & $(0.335)$ \\
L2.Log market share & & & $-0.419^{* *}$ & \\
& & & $(0.168)$ & \\
$\mathrm{N}$ & 180 & 150 & 120 & 150 \\
$\mathrm{R}^{2}$ & 0.312 & 0.441 & 0.484 & 0.570 \\
Method & OLS & OLS & OLS & OLS \\
\hline \hline
\end{tabular}

Table 1: OLS regression on price growth

Notes: Standard errors are clustered at the industry level and displayed in parentheses. *** significant at 1 percent, $* *$ significant at 5 percent, * significant at 10 percent. All regressions include year fixed effects (4-6 intervals) and industry fixed effects (30 groups). The total sample period runs from 1977-2007, but observations are grouped into five-year intervals. The independent variable is averaged over five years, the dependent variable is calculated as the five-year log-difference. "L." and "L2." denotes a one and two period lag respectively (i.e. $l=5$ and $l=10$ in equation (56)). 
positive effect of a larger market size on the TFP growth rate. Table 2 presents our estimates using the five-year TFP growth rates as the dependent variable. Qualitatively the same picture as in Table 1 remains, even though the effects are slightly smaller in magnitude and less precisely estimated.

The identification strategy of the OLS regressions relies on the assumption that Dependent variable: TFP growth rate

\begin{tabular}{lcccc}
\hline \hline & $(1)$ & $(2)$ & $(3)$ & $(4)$ \\
\hline Log market share & -0.104 & & & $-0.533^{* *}$ \\
& $(0.071)$ & & & $(0.260)$ \\
L.Log market share & & $0.241^{* *}$ & & $0.593^{* *}$ \\
& & $(0.119)$ & & $(0.247)$ \\
L2.Log market share & & & $0.145^{*}$ & \\
& & & $(0.081)$ & \\
N & 180 & 150 & 120 & 150 \\
$\mathrm{R}^{2}$ & 0.489 & 0.549 & 0.587 & 0.624 \\
Method & OLS & OLS & OLS & OLS \\
\hline \hline
\end{tabular}

Table 2: OLS regression of TFP growth

Notes: Standard errors are clustered at the industry level and displayed in parentheses. *** significant at 1 percent, ** significant at 5 percent, * significant at 10 percent. All regressions include year fixed effects (4-6 intervals) and industry fixed effects (30 groups). The total sample period runs from 1977-2007, but observations are grouped into five-year intervals. The independent variables are averaged over five years, the dependent variable is calculated as the five-year log-difference. "L." and "L2." denotes a one and two period lag respectively (i.e. $l=5$ and $l=10$ in equation (56)).

firms - that make the R\&D investment decision - do take the industry market size as exogenously given. However, this might not be the case. Especially, some large firms might take into account that their innovation activity can affect the industry price index and consequently their market size. Depending on the elasticity of substitution this would bias our estimate up- or downwards. To address this concern we offer an IV strategy where we instrument the industry market size by its compo- 
nent stemming from the structural change at the final consumption level. This is in line with our theory, where structural change at the final good level trickles down via the input-output structure of the economy - to the industry value-added level, where it determines the incentive to innovate.

Hence, in order to construct our instrument we require the U.S. input-output tables. We first have to close the gap between purchaser's prices and producer's prices. ${ }^{18}$ This is done by the "Personal Consumption Expenditure Bridge Table". Then the input-output tables of the year 2002 are used to calculate how much nominal value-added in industry $i$ is needed in order to produce one U.S. dollar sale of final consumption good $j$. As in the theoretical section we denote this requirement coefficient as $\alpha_{j}(i)$. Given the gross nominal consumption, $p_{j} y_{j}$, of 76 final consumption sectors $j=1, \ldots, Q$ and these intensities $\alpha_{j}(i)$, we can then construct for each industry and year the "potential" market size

$$
\tilde{v a}_{i}(\tau)=\sum_{j=1}^{Q} \alpha_{j}(i) p_{j}(\tau) y_{j}(\tau) .
$$

This potential market size is the value-added that would have been generated in industry $i$ if the intensities would have been the same as in the year 2002. With this potential market size we can calculate our instrument, the potential market share, as

$$
\tilde{s}_{i}(t-l)=\frac{1}{5} \sum_{k=1}^{5} \frac{\tilde{v a}(t-l-k)}{E(t-l-k)},
$$

\footnotetext{
${ }^{18}$ The producer's price of a good is the value the producer obtains when the good leaves the factory, while the purchaser's price is the price the consumer pays in a store when buying the good. Thus, the main difference is that the later contains distribution costs (like sales tax or transportation costs) while the former does not.

A detailed application of input-output tables is found in Online Appendix B.
} 
where the denominator is simply total consumer expenditures $E(t-l-k)=$ $\sum_{j=1}^{Q} p_{j}(t-l-k) y_{j}(t-l-k) .{ }^{19}$ The identifying assumption of this instrument is that individual firms consider the final sales in the 76 consumption categories as exogenously given. More specifically, firms do not consider that their own R\&D investments can affect the price indices of the different final consumption categories and consequently their market size. For example, the assumption is that a single tire producer takes the market size of newly sold cars as exogenously given and does not consider it to be influenceable by his own R\&D investments.

Table 3 and 4 and summarize the results when we instrument the market share, $s_{i}(t-l)$, by our measure of potential market share. ${ }^{20}$ The effects on both the price growth rate and the industry specific TFP growth are slightly higher, but qualitatively they show the same, consistent pattern: The coefficients of the one period lagged variables is large and statistically significant at least at the five percent level. With a two period lag, the coefficients get smaller and the contemporaneous effects are small (and at least in the case of the TFP growth insignificant). The coefficient in column (2) of Table 4 suggests that a one percent increase in its market share increases the industry specific TFP growth rate by 0.3 percentage points over the next five years. Given the average five-year TFP growth rate of 4.3 percent, this is an economically significant effect.

\footnotetext{
${ }^{19}$ Note that this measure of total consumer expenditures differs slightly from the one reported in the National Income and Product Accounts (NIPA) since our measure of potential market size corrects for expenditures on imported (intermediate) goods.

${ }^{20}$ The corresponding first stage regressions can be found in Online Appendix A.
} 
Dependent variable: Price growth

\begin{tabular}{lccc}
\hline \hline & $(1)$ & $(2)$ & $(3)$ \\
\hline Log market share & $-0.210^{* *}$ & & \\
& $(0.096)$ & & \\
L.Log market share & & $-0.602^{* * *}$ & \\
& & $(0.232)$ & $-0.437^{* *}$ \\
L2.Log market share & & & $(0.199)$ \\
\hline $\mathrm{N}$ & & & 120 \\
$\mathrm{R}^{2}$ & 180 & 150 & 0.483 \\
Method & 0.279 & 0.438 & IV \\
\hline \hline
\end{tabular}

Table 3: IV regression on price growth

Notes: Standard errors are clustered at the industry level and displayed in parentheses. *** significant at 1 percent, ** significant at 5 percent, $*$ significant at 10 percent. All regressions include year fixed effects (4-6 intervals) and industry fixed effects (30 groups). The total sample period runs from 1977-2007, but observations are grouped into five-year intervals. The independent variables are averaged over five years, the dependent variable is calculated as the five-year log-difference. The Log market share is instrumented by the structural change at the final consumption good level as described in Section 4.1. First stage regression results are found in Online Appendix A. "L." and "L2." denotes a one and two period lag respectively (i.e. $l=5$ and $l=10$ in equation (56)). 
Dependent variable: TFP growth

\begin{tabular}{lccc}
\hline \hline & $(1)$ & $(2)$ & $(3)$ \\
\hline Log market share & 0.090 & & \\
& $(0.102)$ & & \\
L.Log market share & & $0.296^{* *}$ & \\
& & $(0.144)$ & \\
L2.Log market share & & & $0.209^{* *}$ \\
& & & $(0.098)$ \\
\hline $\mathrm{N}$ & 180 & 150 & 120 \\
$\mathrm{R}^{2}$ & 0.459 & 0.547 & 0.584 \\
Method & $\mathrm{IV}$ & $\mathrm{IV}$ & $\mathrm{IV}$ \\
\hline \hline
\end{tabular}

Table 4: IV regression on TFP growth

Notes: Standard errors are clustered at the industry level and displayed in parentheses. *** significant at 1 percent, ** significant at 5 percent, $*$ significant at 10 percent. All regressions include year fixed effects (4-6 intervals) and industry fixed effects (30 groups). The total sample period runs from 1977-2007, but observations are grouped into five-year intervals. The independent variables are averaged over five years, the dependent variable is calculated as the five-year log-difference. The Log market share is instrumented by the structural change at the final consumption good level as described in Section 4.1. First stage regression results are found in Online Appendix A. "L." and "L2." denotes a one and two period lag respectively (i.e. $l=5$ and $l=10$ in equation (56)). 


\section{Conclusion}

This paper presented a parsimonious model of industry directed technical change where households have non-homothetic preferences. Within our theoretical framework we show how structural change at the final output level translates into structural change at the industry value-added level. In line with the directed technical change literature, the industry specific market share is the key determinant of R\&D investments. A change in households' expenditure profile leads to a systematic shift in industry specific TFP growth rates and consequently relative prices. However, the changing relative prices themselves create a feedback effect on households' expenditure structure. Hence, our model also incorporates the relative price channel of structural change. Although replicating this rich disaggregate structure, the model features constant growth on the aggregate and has a closed form solution.

Building on our theoretical model, we evaluated the market size effect empirically. Working with input-output tables, we constructed a measure of market size that is driven by an arguably exogenous component of structural change at the final output level. Our identification strategy then allowed us to evaluate the importance of the market size hypothesis across the complete set of U.S. industries. Robust to different specifications, we find that a one percent increase in an industry's market share increases its TFP growth rate by about 0.3 percentage points or equivalently reduces its price growth by -0.6 percentage points (over a five year period). Consistent with our expectation, we also document that while $R \& D$ investments react simultaneously to an increase in market size, it takes about 5 years for these investments to result in larger TFP growth rates and falling prices.

Our results can be read as a qualification to the "Baumol's cost disease", which states that with an elasticity of substitution smaller than unity, sectors with a lower TFP growth rate account for an increasing fraction of total GDP and consequently, the economy's aggregate growth rate declines as sectors with lower technical progress 
constitute a larger fraction of the economy. Our qualification is twofold: First, we emphasize the non-homotheticity of preferences as a driver of structural change. If the production process of luxuries (with an expenditure elasticity of demand larger than one) exhibited faster technical change, there might be no cost disease - even if the elasticity of substitution were less than unity. The second challenge is due to the endogenous direction of technical change. If - as our results suggest - bigger markets attract more $R \& D$ investments, the TFP growth rate of faster expanding sectors will endogenously increase. Consequently, the ranking of the sectors along the rate of technical progress is not stable over time. The sectors that feature today a low rate of technical change and account for an increasing fraction of GDP might transform into tomorrow's engine of technical progress. 


\section{References}

Acemoglu, D. (1998), "Why Do New Technologies Complement Skills? Directed Technical Change and Wage Inequality", The Quarterly Journal of Economics, 113, 1055-1089.

Acemoglu, D. (2002), "Directed Technological Change", The Review of Economic Studies, 64, 781-809.

Acemoglu, D. (2009). "Modern Economic Growth", Princeton, New Jersey: Princeton University Press.

Acemoglu, D. and Guerrieri, V. (2008), "Capital Deepening and Nonbalanced Economic Growth", Journal of Political Economy, 116, 467-497.

Acemoglu, D. and Linn, J. (2004), "Market Size and Innovation: Theory and Evidence from the Pharmaceutical Industry", The Quarterly Journal of Economics, 119, 1049-1090.

Acemoglu, D. and Zilibotti, F. (2001), "Productivity Differences", The Quarterly Journal of Economics, 116, 563-606.

Aghion, P. and Howitt, P. (1992), Endogenous Growth Theory, MA: MIT Press.

Baumol, W. (1967), "Macroeconomics of Unbalanced Growth: The Anatomy of Urban Crisis", American Economic Review, 57, 415-426.

Bureau of Economic Analysis (BEA), U.S. Department of Commerce (2009), "Concepts and Methods of the U.S. National Input-Output Accounts", Ch.1-12.

Bureau of Economic Analysis (BEA), U.S. Department of Commerce (2011), "Concepts and Methods of the U.S. National Income and Product Accounts", Ch.19. 
Boppart, T. (2011), "Structural change and the Kaldor facts in a growth model with relative price effects and non-Gorman preferences", University of Zurich Department of Economics Working Paper No. 2.

Browning, M. (2008), "Engel's Law", The New Palgrave Dictionary of Economics, Second Edition, Eds. Steven N. Durlauf and Lawrence E. Blume, Palgrave Macmillan.

Engel, E. (1857), "Die Productions- und Consumptionsverhaeltnisse des Koenigsreichs Sachsen", Zeitschrift des Statistischen Bureaus des Königlich Sächsischen Ministeriums des Inneren, No. 8 and 9.

EUKLEMS consortium (2007), "EU KLEMS Growth and Productivity Accounts, Part I Methodology", Version 1.0, prepared by Timmer, M. , van Moergastel, T., Stuivenwold, E., Ypma, G. and O’Mahony, M. and Kangasniemi, M..

EUKLEMS consortium (2007), "EU KLEMS Growth and Productivity Accounts, Part II Sources by Country", Version 1.0, prepared by Timmer, M. , van Moergastel, T., Stuivenwold, E., Ypma, G. and O’Mahony, M. and Kangasniemi, M..

Feldman, S., McClain, D. and Palmer, K. (1987), "Sources of Structural Change in the United States, 1963-1978: An Input-Output Perspective", The Review of Economic Studies and Statistics, 69, 503-510.

Foellmi, R. and Zweimüller, J. (2008), "Structural Change, Engel's Consumption Cycles and Kaldor's Facts of Economic Growth", Journal of Monetary Economics, 55, 1317-1328.

Griliches, Z. (1957), "Hybrid Corn: An Exploration In The Economics of Technological Change", Econometrica, 25, 501-522. 
Griliches, Z. and Schmookler, J. (1963), "Inventing and Maximizing", American Economic Review, 53, 725-729.

Habakkuk, H.J. (1962), American and British Technology in the Nineteenth Century: Search for Labor Saving Inventions, Cambridge: Cambridge University Press.

Hall, B. H., Jaffe, A.B. and Trajtenberg, M. (2001), "The NBER Patent Citations Data File: Lessons, Insights and Methodological Tools", NBER Working Paper 8498.

Herrendorf, B., Rogerson R. and Valentinyi, A. (2009), "Two Perspectives on Preferences and Structural Transformation", NBER Working Paper, 15416.

Herrendorf, B., Rogerson R. and Valentinyi, A. (2011), "Growth and Structural Transformation". Manuscript, Princeton University. Forthcoming in The Handbook of Economic Growth.

Houthakker, H.S. (1957), “An International Comparison of Household Patterns, Commemorating the Century of Engel's Law", Econometrica, 25, 532-551.

Kaldor, N. (1961), "Capital Accumulation and Economic Growth", In The Theory of Capital: Proceedings of a Conference of the International Economic Association, edited by Friedrich A. Lutz and Douglas C. Hague. London: Macmillan.

Kiley,M. (1999), "The Supply of Skilled Labour and Skill-Biased Technological Progress", The Economic Journal, 109, 708-724.

Kleinknecht, A. and Verspagen, B. (1990), "Demand and Innovation: Schmookler re-examined", Research Policy, 19, 387-394. 
Klenow, P. J. (1996), "Industry innovation: where and why", Carnegie-Rochester Conference Series on Public Policy, 44, 125-150.

Klenow, P. J. (1998), "Ideas versus rival human capital: Industry evidence on growth models", Journal of Monetary Economics, 42, 3-23.

Kongsamut, P., Rebelo, S. and Xie, D. (2001), "Beyond Balanced Growth", The Review of Economic Studies, 68, 869-882.

Kuznets, S. (1973), "Modern Economic Growth: Findings and Reflections", American Economic Review, 63, 247-258.

O’Mahony, M., Castaldi, C., Los, B., Bartelsman, E., Maimaiti, Y. and Peng, F. (2008), "EUKLEMS - Linked Data: Sources and Methods", available at www.euklems.net.

O’Mahony, M. and Timmer, M. (2009), "Output, Input and Productivity Measures at the Industry Level: the EU KLEMS Database", The Economic Journal, 119, F374-F403.

Muellbauer, J. (1975), "Aggregation, Income Distribution and Consumer Demand", The Review of Economic Studies, 62, 526-543.

Muellbauer, J. (1976), "Community Preferences and the Representative Consumer", Econometrica, 44, 979-999.

Ngai, R. and Pissarides, C. (2007), "Structural Change in a Multi-Sector Model of Growth", American Economic Review, 97, 429-443.

Pakes, A. and Schankerman, M. (1984), "An Explanation into the Determinants of Research Intensity", 209-232 in RESD, Patents and Productivity edited by Zvi Griliches, Chicago: University of Chicago Press. 
Schmookler, J. (1962), "Economic Sources of Inventive Activity", The Journal of Economic History, 22, 1-20.

Schmookler, J. (1966), Invention and Economic Growth, MA: Harvard University Press.

Staiger, D. and Stock, J. H. (1997), "Instrumental Variables Regression with Weak Instruments", Econometrica, 65, 557-586. 